\title{
ASSESSMENT OF HYDROGEN FLUORIDE DAMAGE TO VEGETATION USING OPTICAL REMOTE SENSING DATA
}

\author{
C. U. Hyun ${ }^{\text {a, }}$, J. S. Lee ${ }^{\text {a }}$ I. Lee ${ }^{\mathrm{a}, *}$ \\ a Spatial Information Research Institute, Korea Cadastral Survey Corporation, Seoul, South Korea \\ - (cuhyun, jaslee, les05)@lx.or.kr
}

KEY WORDS: Hydrogen Fluoride, Vegetation Index, Hyperspectral Imagery, Aerial Photograph, Cadastral map

\begin{abstract}
:
This research assesses damage to vegetation from accidental gaseous hydrogen fluoride leakage, through the analysis of spectral features of the damaged plants using digital aerial photographs and airborne hyperspectral imagery. The hyperspectral imagery was obtained 21 days after the leakage within visible and near-infrared wavelength range using CASI-1500 imager, and two aerial photographs composed of blue, green, red and near-infrared bands were also obtained in October 2, 2011 and November 15, 2012, respectively. The injuries on leaves and the outline of the leakage affected area were assessed by investigating vegetation index images calculated from the hyperspectral imagery and the aerial photograph obtained in November 15, 2012, with comparison to the index image calculated from the aerial photograph obtained in October 12, 2011. The affected areas were mainly distributed in the east of the leakage point, and this reflects predominant wind directions toward east during the leakage and within 24 hours after the leakage. In addition, the detailed changes in spectral reflectance curves of damaged vegetation were also investigated using the hyperspectral imagery. Paddy field and forest land were identified by cadastral map, and the reference areas for the comparison of the reflectance curve change were designated to each land cover type, by considering the most and least affected areas from the vegetation indices comparison results.
\end{abstract}

\section{INTRODUCTION}

Optical remote sensing technique has been successfully applied to monitoring effects from accidental pollution and environmental changes using multi-temporal data analyses. In September 27, 2012, about 8 tons of the hydrogen fluoride was leaked from a chemical factory in Gumi, South Korea, and this leakage caused visible injuries such as chlorosis and necrosis on leaves of trees and crops, which have been well known as typical symptoms of leaves affected from hydrogen fluoride (Linzon, 1986, Ahmad et al., 2012).

The affected areas from the leakage have to be identified and managed to ban on exports of crops produced in the leakage affected area and to pay compensation to the residents who live in the leakage affected area and to employees who work in the leakage affected area.

In this study, airborne hyperspectral imagery and aerial photographs were analysed to determine hydrogen fluoride leakage affected agricultural and forest areas with combining a cadastral map containing simplified land cover and land use information.

\section{STUDY AREA AND DATA SET}

\subsection{Study Area}

The hydrogen fluoride was leaked from a chemical factory located in the boundary of industrial area in Gumi, South Korea (figure 1). Paddy fields, dry fields and forest lands are mainly distributed around the leakage point.

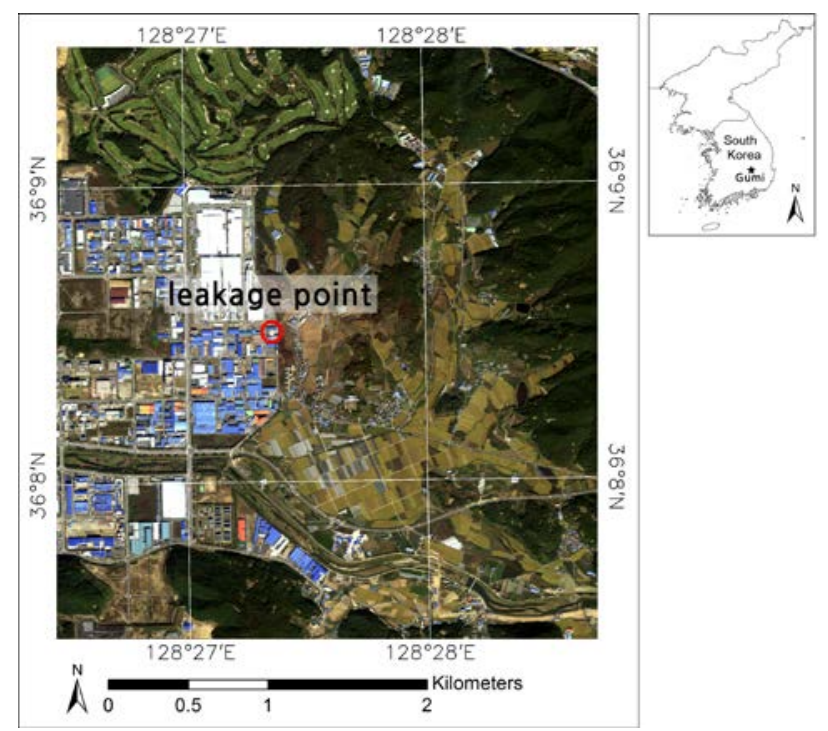

Figure 1. Location and CASI true colour image of the study area

\subsection{Hyperspectral Imagery and Aerial Photographs}

The hyperspectral imagery was obtained 21 days after the leakage within a wavelength range from 365 to 1,050 nm using CASI-1500 imager, and two aerial photographs composed of blue, green, red and near-infrared bands were also obtained in October 12, 2011 and November 15, 2012, respectively. The specifications of the data set are shown in table 1.

\footnotetext{
* Corresponding author
} 


\begin{tabular}{|c|c|c|c|}
\hline Data set & $\begin{array}{c}\text { Hyperspectral } \\
\text { imagery }\end{array}$ & \multicolumn{2}{|c|}{ Aerial photographs } \\
\hline Sensor & CASI-1500 & \multicolumn{2}{|c|}{ UltraCam Xp } \\
\hline $\begin{array}{c}\text { Acquisition } \\
\text { date }\end{array}$ & $\begin{array}{c}\text { October 18, } \\
2012\end{array}$ & $\begin{array}{c}\text { October 2, } \\
2011\end{array}$ & $\begin{array}{c}\text { November 15, } \\
2012\end{array}$ \\
\hline $\begin{array}{c}\text { Spatial } \\
\text { resolution }\end{array}$ & $1 \mathrm{~m}$ & \multicolumn{2}{|c|}{$0.25 \mathrm{~m}$} \\
\hline $\begin{array}{c}\text { Spectral } \\
\text { range }\end{array}$ & $\begin{array}{c}365-1,050 \mathrm{~nm}, \\
48 \text { bands }\end{array}$ & $\begin{array}{c}\text { B }(410-570 \mathrm{~nm}), \\
\text { R (480-630 nm), }\end{array}$ \\
NIR $(690-100 \mathrm{~nm}), 000 \mathrm{~nm})$
\end{tabular}

Table 1. Specifications of hyperspectral imagery and aerial photographs

\subsection{Cadastral Map}

Information of land use and land cover in the study area were examined from cadastral map. The cadastral map is basically composed of simplified 28 land classes and 20 classes among the land classes were included in the study area (table 2). These cadastral land class information were used during the comparison of the effects from the leakage within identical classes, .e.g. paddy fields and forest lands.

\begin{tabular}{|c|c|c|c|}
\hline Class & $\begin{array}{c}\text { Number of } \\
\text { Parcels }\end{array}$ & Class & $\begin{array}{c}\text { Number of } \\
\text { Parcels }\end{array}$ \\
\hline Dry field & 803 & Warehouse & 15 \\
\hline Paddy field & 1332 & Road & 715 \\
\hline Orchard & 253 & Bank & 38 \\
\hline Pasture & 29 & River & 145 \\
\hline Forest land & 348 & Drain & 250 \\
\hline $\begin{array}{c}\text { Residential } \\
\text { land }\end{array}$ & 570 & $\begin{array}{c}\text { Pool and } \\
\text { Reservoir }\end{array}$ & 72 \\
\hline Factory & 221 & Park & 33 \\
\hline School & 2 & Play ground & 104 \\
\hline Parking space & 5 & Grave yard & 10 \\
\hline Gas station & 2 & $\begin{array}{c}\text { Miscellaneous } \\
\text { area }\end{array}$ & 54 \\
\hline
\end{tabular}

Table 2. Cadastral land classes within the study area

\subsection{Weather Data}

To investigate spatial characteristics of the leakage affected area, hourly measured weather data including wind directions and speeds were collected for 21 days from the date of leakage to the acquisition date of the hyperspectral imagery. The weather data were measured in the weather station located about $12 \mathrm{~km}$ apart from the leakage point.

\section{METHODOLOGY}

A detailed workflow for the preprocessing and analysis steps conducted in this study is shown in figure 2 .

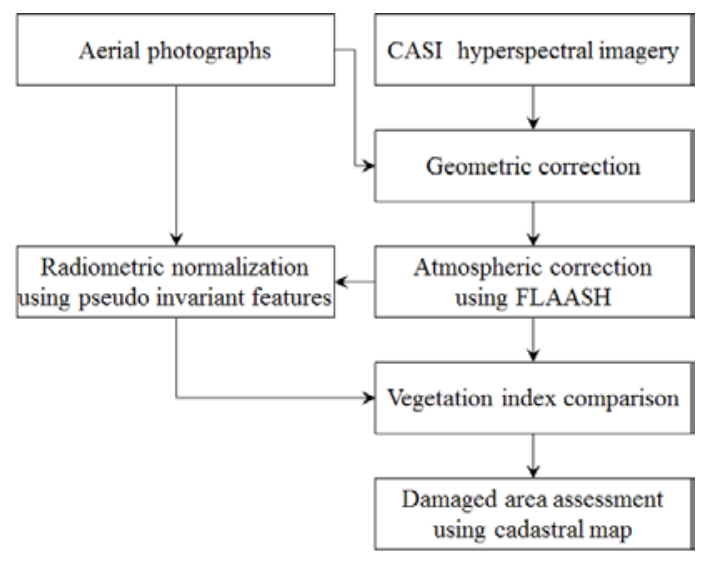

Figure 2. Workflow chart for the processing used in this study

\subsection{Preprocessing of Data Set}

The CASI hyperspectral imagery was registered with the aerial photographs and then atmospherically corrected using the FLAASH module of ENVI software. The aerial photographs were radiometrically normalized using pseudo invariant features, e.g. large roofs of factories consist of artificial materials, to directly compare the vegetation index image from the hyperspectral imagery.

\subsection{Vegetation Index}

The gas leakage effects on vegetation were assessed by comparing normalized difference vegetation index (NDVI) images. The formula of NDVI follows (Rouse et al., 1974):

$$
\text { NDVI }=\left(\rho_{\text {NIR }}-\rho_{\text {red }}\right) /\left(\rho_{\text {NIR }}+\rho_{\text {red }}\right)
$$

where $\rho=$ reflectance at a specific band or wavelength

The NDVI was designed for broad band data, e.g. multi-spectral image, so the wavelengths of hyperspectral imagery for calculation of NDVI were designated to the centre of wavelength ranges of corresponding bands of the aerial photograph, i.e. $640 \mathrm{~nm}$ as the red band and $845 \mathrm{~nm}$ as the NIR band.

\section{RESULTS}

\subsection{Assessment of Damage to Vegetation}

The NDVI was calculated for the aerial photographs and the values higher than 1 caused by artificial land covers were masked out (figure 3 (a) and (b)). The NDVI using the hyperspectral imagery is shown in figure 3 (c) cropped for the area around the leakage point. Decrease of NDVI values in the eastern parts of the leakage point was identified from both NDVI images from the aerial photographs and the hyperspectral imagery acquired after the leakage. The difference image (figure 4) between the aerial photographs reflects general trend of locality of damaged vegetation. The areas showing high difference values in the upper left and the bottom parts of the difference image are the vegetation removed areas due to construction activities. 


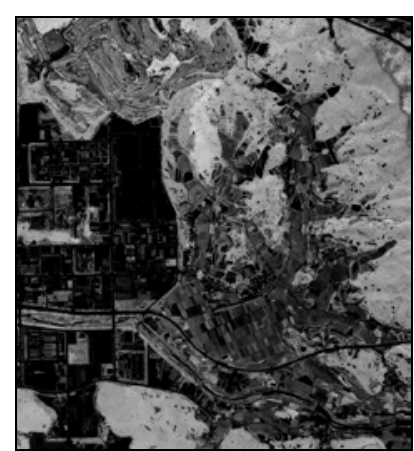

(a)

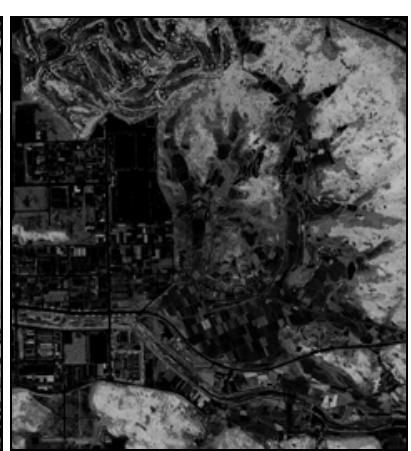

(b)

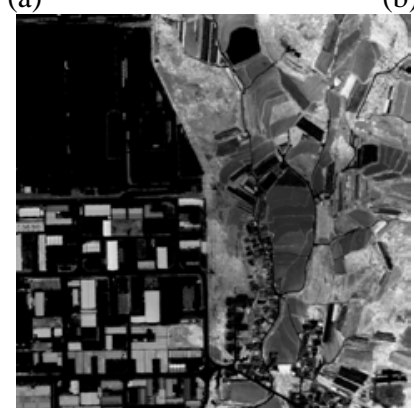

(c)

Figure 3. Vegetation index images: (a) NDVI (stretched between 0.1 and 0.9 ) of the aerial photo acquired in October 2, 2011, (b) NDVI (stretched between 0.1 and 0.9 ) of the aerial photo acquired in November 15, 2012 and (c) NDVI (stretched between 0.1 and 0.9 ) of the hyperspectral imagery cropped around the leakage point

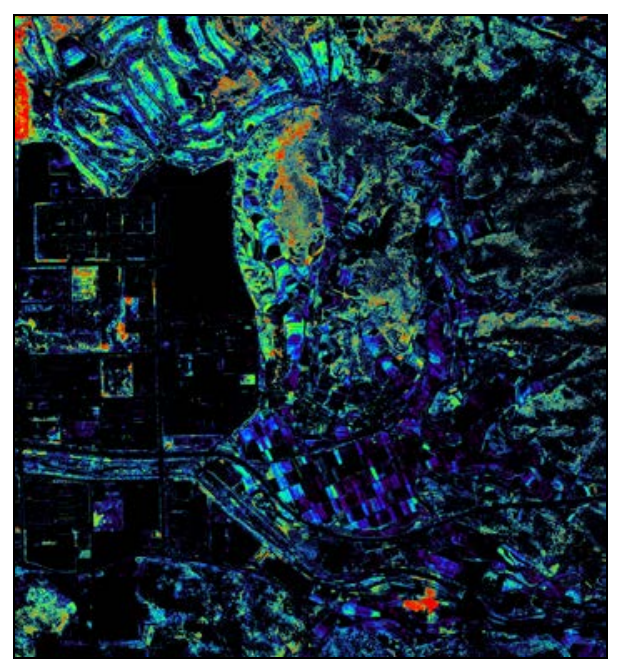

Figure 4. Differences between the NDVI values (stretched between 0.1 and 0.4 of difference values) from the aerial photographs (red colour indicates higher differences and blue colour indicates lower differences)

To compare spectral reflectance curves of paddy fields and forest lands, gas leakage affected and unaffected areas were selected from the most and least affected areas and then their spectral reflectance curves are illustrated in figure 5. Typical spectral reflectance characteristics of vegetation were eliminated in the damaged paddy field and forest land.
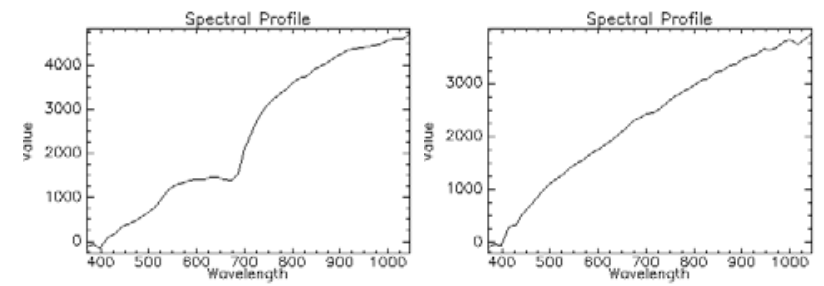

(a)
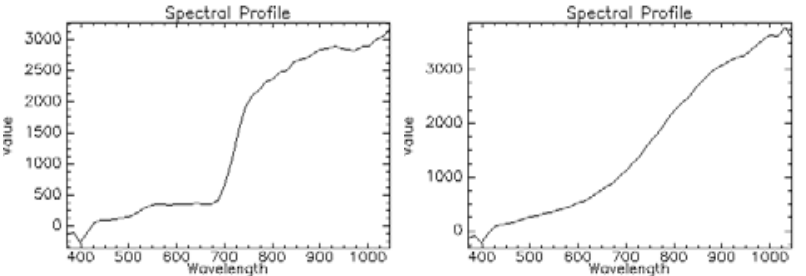

(b)

Figure 5. Spectral reflectance curves of the normal and leakage affected area: (a) paddy field and (b) forest land

\subsection{Cadastral Map Overlapping}

The affected parcels from the leakage were identified on the cadastral map (figure 6). The parcels mainly consist of paddy fields and forest lands, and the paddy fields can be considered to be banned on exports of crops produced.

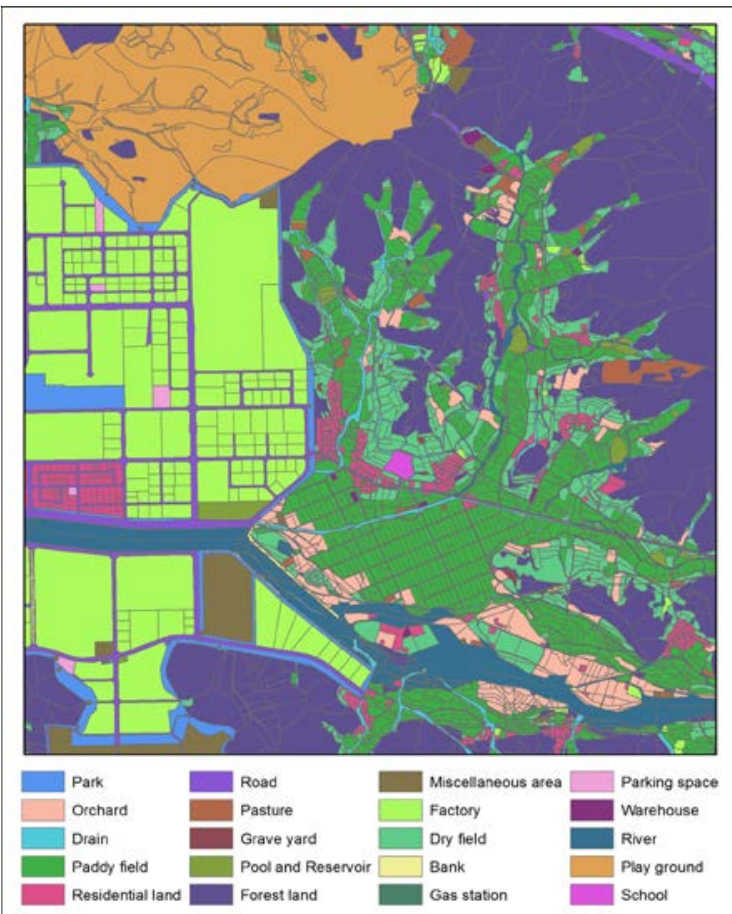

Figure 6. Cadastral map of the study area

\subsection{Analysis of Weather Data}

Wind directions measured by the directions from which it originates were analysed to investigate movement of the gas after leakage (figure 7). The wind directions dominantly from west during 24 hours after the leakage and during 21 days after the leakage reflect more damaged vegetation in eastern area of the gas leakage point. The averaged wind speeds during 24 hours after the leakage was about $1.1 \mathrm{~m} / \mathrm{sec}$ and this calm weather condition might cause stationary movement of the gas. 


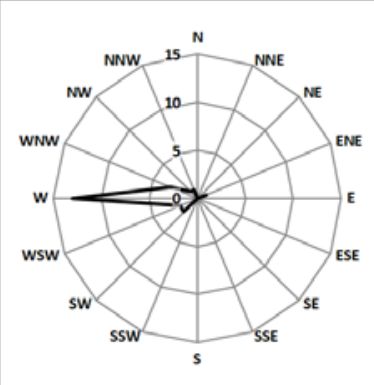

(a)

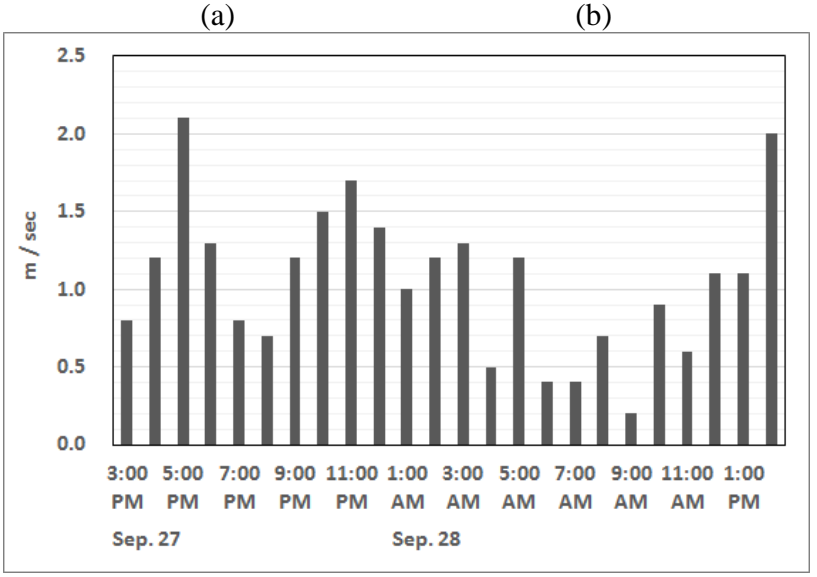

(c)

Figure 7. Weather data after the leakage: (a) wind directions during 24 hours after the leakage, (b) wind directions during 21 days after the leakage and (c) wind speeds during 24 hours after the leakage

\section{CONCLUSIONS}

The localities of vegetation showing hydrogen fluoride damages were identified by comparing the vegetation index images and the spectral reflectance curves, and this result can be used to update the cadastral map for the purpose of polluted areas management, e.g., ban on exports of crops produced in the leakage affected area and paying compensation to the residents who live in the leakage affected area and to the employees who work in the leakage affected area. In this study, simple vegetation index was used but application of chlorophyll indices, e.g. modified chlorophyll absorption in reflectance index (MCARI) (Daughtry et al., 2000) or transformed CARI (TCARI) (Haboudane et al., 2002), using hyperspectral narrow bands can be meaningful due to the decrease of chlorophyll contents of the vegetation affected by hydrogen fluoride (Pandey, 1985).

\section{ACKNOWLEDGEMENTS}

This study was supported by the Spatial Information Research Institute, Korea Cadastral Survey Corporation. The authors appreciate the hyperspectral imagery from Saehan Aerial Survey Co., Ltd. and Geostory, Inc. and the aerial photographs from Samah Aerial Survey, Co., Ltd.

\section{REFERENCES}

Ahmad, M.N., van den Berg, L.J.L., Shah, H.U., Masood, T., Büker, P., Emberson, L., and Ashmore, M., 2012. Hydrogen fluoride damage to vegetation from peri-urban brick kilns in
Asia: A growing but unrecognised problem?. Environmental Pollution, 162, pp. 319-324.

Daughtry, C.S.T., Walthall, C.L., Kim, M.S., Brown de Colstoun, E., and McMurtrey III, J.E., 2000. Estimating corn leaf chlorophyll concentration from leaf and canopy reflectance. Remote Sensing of Environment, 74(2), pp. 229-239.

Haboudane, D., Miller, J.R., Tremblay, N, Zarco-Tejada, P.J., and Dextraze, L., 2002. Integrated narrow-band vegetation indices for prediction of crop chlorophyll content for application to precision agriculture. Remote Sensing of Environment, 81(2-3), pp. 416-426.

Linzon, S.N., 1986. Effects of gaseous pollutants on forests in eastern North America. Water, Air and Soil Pollution, 31(3-4), pp. 357-550.

Pandey, G.P., 1985. Effects of gaseous hydrogen fluoride on leaves of Terminalia tomentosa and Buchanania lanzan trees. Environmental Pollution, 37, pp. 323-334.

Rouse, J.W., Haas, R.H., Schell, J.A., Deering, D.W., and Harlan, J.C., 1974. Monitoring the vernal advancements and retrogradation of natural vegetation. NASA/GSFC final report, MD, USA, Greenbelt. 